\title{
Monitoring of people and workers exposure to the electric, magnetic and electromagnetic fields in an Italian national cancer Institute
}

\author{
Anna Maria Di Nallo* ${ }^{* 1}$, Lidia Strigari ${ }^{\dagger 1}$, Claudia Giliberti ${ }^{\dagger 2}$, \\ Angelico Bedini ${ }^{\dagger 2}$, Raffaele Palomba ${ }^{\dagger 2}$ and Marcello Benassi ${ }^{\dagger 1}$
}

Address: ${ }^{1}$ Laboratorio di Fisica Medica e Sistemi Esperti Regina Elena National Cancer Institute, Rome, Italy and ${ }^{2}$ Dipartimento Insediamenti Produttivi ed Interazione con l'Ambiente Italian National Institute for Health and Safety at Work, Rome, Italy

Email: Anna Maria Di Nallo* - dinallo@ifo.it; Lidia Strigari - strigari@ifo.it; Claudia Giliberti - Claudia.Giliberti@ispesl.it; Angelico Bedini - Angelico.Bedini@ispesl.it; Raffaele Palomba - Raffaele.Palomba@ispesl.it; Marcello Benassi - benassi@ifo.it

* Corresponding author †Equal contributors

\begin{abstract}
Background: The paper reports the electric, magnetic and electromagnetic fields (emf) measurements carried out in the Regina Elena National Cancer Institute (NCI). Several devices, used in diagnostics and in medical cures, can represent sources of emf for the workers and for the public subjected to the treatments. The aim is to evaluate their exposition, in order to assess the compliance with the law.
\end{abstract}

Methods: The investigations have been carried out in the departments of: intensive care, physiotherapy, MR presstherapy and in the surgical rooms. The measurements have been performed using broad band probes in the frequency ranges $5 \mathrm{~Hz} \div 30 \mathrm{kHz}$ and $100 \mathrm{kHz}-3 \mathrm{GHz}$.

Results: The variability of the magnetic induction $(B(\mu \mathrm{T}))$ levels is between $0,05 \mu \mathrm{T}$ and $80 \mu \mathrm{T}$. The statistical distribution shows that most of the measurements are in the range $0,05<B=0,5 \mu T$ and the $89 \%$ of the $B(\mu \mathrm{T})$ levels are within the $3 \mu \mathrm{T}$.

Conclusion: The measurement of the emf levels in the $\mathrm{NCl}$ is recommended because of the presence of the oncological patients; their long stay near the equipments and their day-long exposure represent additional risk factors for which a prudent avoidance strategy have to de adopted.

\section{Background}

In the last years, the increase in the number of systems for telecommunications and for the electric energy transport, has produced a huge debate both in the scientific community and among the public on the potential risks on health due to long time exposition to the electric field $(e f)$, magnetic field $(\mathrm{mf})$ and electromagnetic field (emf) in the working and living environments. The effects produced by the interaction of these physical agents with the biological systems depend on frequency, amplitude of the fields and on the time of the exposition. The effects can be classified in thermal and non-thermal [1]. The former are scientifically well-know and consist in heat production in the biological system; the exposure limits recommended by the 
national and international legislation protect from this injury. The existence of the non-thermal effects represents an open issue; they concern the evidence of biological changes without an effective increase of temperature. The scientific debate is centred on the issue if a long exposition to $e f-m f$-emf levels lower than the limits could cause harmful effects on health. Many national and international research projects are involved in this investigation by in vivo, in vitro and epidemiological studies. [2-7]. Until now, conclusive results are still not available.

In Italy, the issue of people exposition to the ef-mf-emf is regulated by two decrees promulgated in 2003, one for fields produced by sources with frequencies between 100 $\mathrm{kHz}$ and $300 \mathrm{GHz}$ [8], the other for power lines at the frequency of $50 \mathrm{~Hz}$ [9]. Their distinctive feature is to establish people long term exposure levels to ef-mf-emf lower than the limits recommended by the international standards fixed by the International Commission on non-ionizing radiation protection (ICNIRP) [10]. For sources not referable to power lines in the frequency range $0 \mathrm{~Hz}-100 \mathrm{kHz}$, the whole of the restrictions fixed by the European Council Recommendation of 12 July 1999 [11] has to be considered. About the workers, the directive 2004/40/EC [12], recently incorporated into the Italian legislation system with the decree n. 257/2007 [13], has to be applied.

The main aim of this paper is to report the ef-mf-emf measurements carried out in the Regina Elena National Cancer Institute (NCI). Several electric and electronic devices, used in diagnostics and in medical cures, have been investigated, which can represent potential sources of ef-mf-emf for the health staff, for the public subjected to the treatments and also for their accompanists. The main peculiarity of this study is then to verify the exposition to these physical agents for a class of particularly vulnerable patients, as the oncological ones, in order to assess the compliance with the law. The long stay of these patients near the equipments and their day-long exposure can represent additional risk factors for which a prudent avoidance strategy has to be adopted.

\section{Methods}

The investigations have been carried out in the intensive care division, the physiotherapy department, the surgical rooms, the Magnetic Resonance (MR) department and the press-therapy room. For each division, the investigated equipments are reported in Table 1 . The study has been extended also to a wireless equipment for internal communications and to external sources.

Initially, the technical characteristics of each equipment have been collected. Moreover, their operating modalities during diagnostic and therapy sessions, and their localizations in each area have been acquired, in order to detect potential interactions.

The measurements have been performed using a broad band probe (EMR 300 Wandel \& Goltermann) providing the total electric field for the frequency range $100 \mathrm{kHz}-3$ GHz. According with the Italian decrees [8,9], the length of time of each measurement was six minutes. For the frequencies range $5 \mathrm{~Hz} \div 30 \mathrm{kHz}$, the EFA-3 Wandel \& Goltermann, equipped with an external magnetic probe, has been used. All the measurements have been carried out in the operating clinical conditions.

The check on the external sources has been executed using the narrow band device SRM3000 Narda, equipped with

Table I: Equipments investigated in each division of the NCI-IRE

\begin{tabular}{|c|c|c|}
\hline Divisions & Equipments & Manufacturer \\
\hline \multirow[t]{6}{*}{ Physiotherapy division } & Electro-stimulators & Biorem TENS \\
\hline & Electro-stimulators & Biorem ionophoresis (IP) \\
\hline & Laser therapy & Leve Laser \\
\hline & Ultrasound therapy & Radar Biorem \\
\hline & Cyclette & Technogym \\
\hline & Pressotherapy & Linfopress Fisioline \\
\hline \multirow[t]{2}{*}{ Press-therapy room } & Lymphatic Drainage & Linfopress \\
\hline & Lymphatic Drainage & Linfopress studio \\
\hline \multirow[t]{5}{*}{ Intensive care division } & Workplaces - PC & Philips \\
\hline & Electric panel & FAAE \\
\hline & Monitor & Philips \\
\hline & Ventilator & Dräger \\
\hline & Pump & Abbott \\
\hline \multirow[t]{2}{*}{ Surgical rooms } & Ventilator & Dräger \\
\hline & Electric scalpel & Martin/Conmed \\
\hline MR & Magnetic Resonance & Philips (0,5 T) \\
\hline Other departments & DECT & Alcatel \\
\hline
\end{tabular}


Table 2: The magnetic induction measurements near the tapis roulant (fig.l)

\begin{tabular}{cc}
\hline Points of measurements & B $(\mu \mathbf{T})$ \\
\hline 1 & 4,5 \\
2 & 0,03 \\
3 & 0,01 \\
4 & 0,03 \\
5 & 0,02 \\
\hline
\end{tabular}

an isotropic probe working in the frequency range 75 $\mathrm{MHz}-3 \mathrm{GHz}$.

\section{Results and discussion}

\section{(a) Physiotherapy department}

The physiotherapy department $(12 \times 3 \mathrm{~m})$ includes an open space, where cyclettes and tapis roulant are positioned, and n. 4 boxes where the devices for specific therapies (Table 1) can be placed on demand. Broad band electric field measurements, carried out in the open space, with all the equipments working in operating conditions, have supplied values lower than the sensitivity of the electric field probe $(1,0 \mathrm{~V} / \mathrm{m})$. In table 2 and 3 are reported the results of the magnetic induction $(\mathrm{B}(\mu \mathrm{T}))$ measurements respectively near the tapis roulant (Fig. 1) and specific equipments, conveniently placed in one box (Fig. 2). $\mathrm{B}(\mu \mathrm{T})$ levels are generally lower than $1 \mu \mathrm{T}$, with few exceptions, near the tapis roulant $(4,5 \mu \mathrm{T})$, and near the press-therapy equipment, where a maximum $\mathrm{B}(\mu \mathrm{T})$ level of 1,6 $\mu \mathrm{T}$ has been registered. Effective electric field $\left(\mathrm{E}_{\text {eff }}(\mathrm{V} / \mathrm{m})\right)$ levels lower than 2,3 V/m have been registered near the equipment for ultrasound therapy. Further measurements, performed near the head of the Laser Power Diode, have provided $\mathrm{E}_{\text {eff }}(\mathrm{V} / \mathrm{m})$ measurements in the range 1,0 -3,0 V/ m.

\section{(b) Press-therapy room}

The rehabilitation area consists of: the reception, the press-therapy room and a medical office. In particular, in the press-therapy room, two equipments for the arms Lymphatic Drainage are placed. The duration of this therapeutic treatment varies from 2 hours up to 4 hours and is generally performed for four patients at the same time. The $\mathrm{B}(\mu \mathrm{T})$ levels, measured in the points reported in Fig. 3 , are reported in Table 4.

During the treatments, the $\mathrm{B}(\mu \mathrm{T})$ levels detected near the patients are lower than $1 \mu \mathrm{T}$. Around the equipments, in positions where only the staff could eventually stay, $\mathrm{B}(\mu \mathrm{T})$ levels between 1,1 and 5,0 $\mu \mathrm{T}$ have been registered. Higher levels (up to $80 \mu \mathrm{T}$ ) have been obtained near the air compressors and the electronics of the equipments, in the positions reported in Table 4. Additional measurements, performed at a height of about $10 \mathrm{~cm}$ from the floor, have provided $\mathrm{B}(\mu \mathrm{T})$ levels lower than 1,4 $\mu \mathrm{T}$. Further investigations, carried out in the contiguous rooms, during the equipments standard working conditions, provided $\mathrm{B}(\mu \mathrm{T})$ values between 0,1 and $0,2 \mu \mathrm{T}$.

\section{(c) Intensive care division}

The intensive care division consists of an open space, where three patients' beds and two monitoring workplaces are located, and three rooms. In Table 5, the results of the $\mathrm{B}(\mu \mathrm{T})$ measurements in the open space (Fig. 4) near the sources listed in Table 1, are reported; the magnetic induction measurements, carried out at a height of 1,0 m and $1,9 \mathrm{~m}$ from the floor, near the electric panel and near the intensive care staff workplaces, are lower than 1,9 $\mu \mathrm{T}$. Magnetic field background measurements in the open space provided $\mathrm{B}(\mu \mathrm{T})$ levels equal to $70 \mathrm{nT}$. The high frequencies $\mathrm{E}_{\text {eff }}(\mathrm{V} / \mathrm{m})$ values, measured near a patient's bed, resulted lower than $1,0 \mathrm{~V} / \mathrm{m}$. In Table 5 , the results of the $\mathrm{B}(\mu \mathrm{T})$ measurements around a bed (Fig. 5) are reported. The $\mathrm{B}(\mu \mathrm{T})$ levels close to the patients are lower than $1 \mu \mathrm{T}$, while levels up to 7,0 $\mu \mathrm{T}$ have been detected at $1 \mathrm{~m}$ from the bed, at a distance of few centimetres from the volumetric and syringe infusion pumps. Higher $\mathrm{B}(\mu \mathrm{T})$ levels (equal to $14 \mu \mathrm{T}$ ) have been measured at the bottom of the bed near the engine of the anti-bedsore mattress.

Table 3: The magnetic induction $B(\mu T)$ and effective electric field $E_{\text {eff }}(V / m)$ levels in the box described in fig. 2

\begin{tabular}{|c|c|c|c|c|c|}
\hline \multirow[t]{3}{*}{ Points } & \multicolumn{2}{|c|}{ Electro stimulator equipment } & \multirow[t]{2}{*}{ Press-therapy equipment } & \multicolumn{2}{|c|}{ Ultrasounds therapy equipment } \\
\hline & TENS & IP & & & \\
\hline & $\mathbf{B}(\mu \mathbf{T})$ & $\mathbf{B}(\mu \mathbf{T})$ & $\mathbf{B}(\mu \mathbf{T})$ & $\mathbf{B}(\mu \mathbf{T})$ & $E(\mathrm{~V} / \mathrm{m})(100 \mathrm{kHz} \div 3 \mathrm{GHz})$ \\
\hline 1 & 0,2 & 0,2 & 0,5 & 0,1 & $<1$ \\
\hline 2 & 0,1 & 0,1 & 0,5 & 0,2 & 2,3 \\
\hline 3 & 0,07 & 0,1 & $\mathrm{I}, \mathrm{I}$ & 0,1 & 3 \\
\hline 4 & 0,1 & 0,1 & 0,5 & 0,3 & $<1$ \\
\hline 5 & 0,3 & 1,0 & 1,6 & 0,4 & 2,2 \\
\hline 6 & 0,02 & 0,03 & 0,3 & 0,5 & $<1$ \\
\hline 7 & 0,02 & 0,02 & 0,03 & 0,4 & $<1$ \\
\hline 8 & 0,03 & 0,02 & 0,07 & 0,3 & $<1$ \\
\hline
\end{tabular}




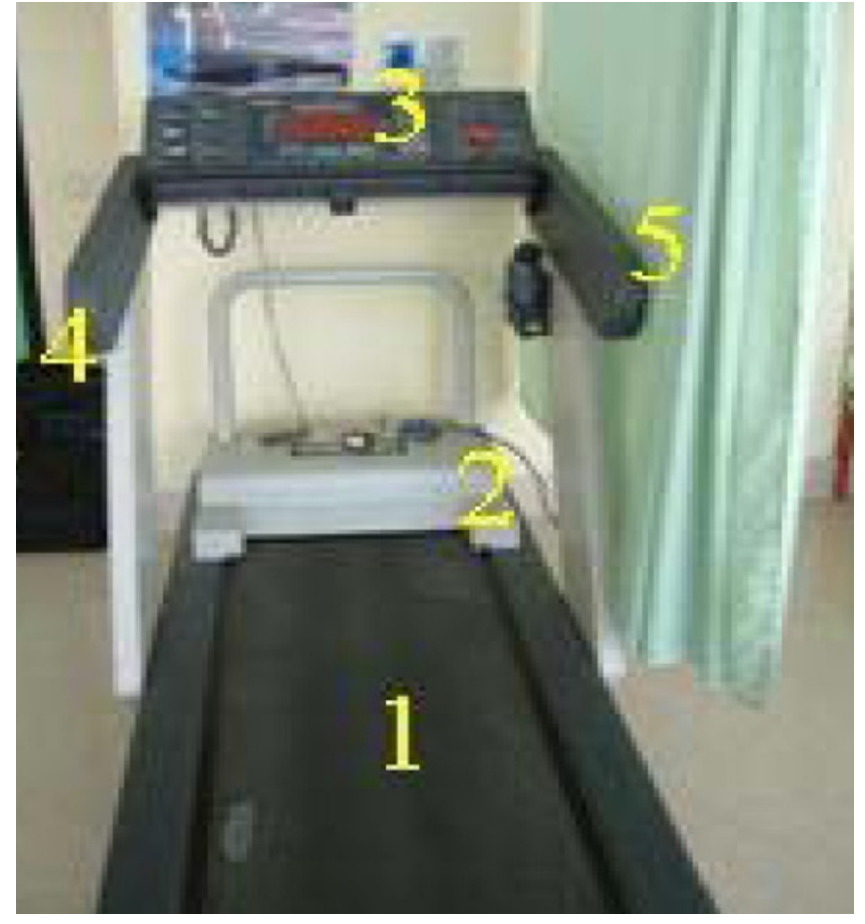

Figure I

Points of measurements near the tapis roulant (detected frequency: $50 \mathrm{~Hz}$ ).

\section{(d) Surgical room}

In the surgical room ( $6 \times 12 \mathrm{~m})$, an operating table and two trolleys equipped with ventilators and electric scalpels are placed. $\mathrm{B}(\mu \mathrm{T})$ measurements, performed with the equipments in working conditions, without patients, provided levels of about $50 \mathrm{nT}$, comparable with the background. Levels up to $24,0 \mu \mathrm{T}$ have been measured near the electric power of the electric scalpels, at $20 \mathrm{~cm}$ from the floor. Broad band $E_{\text {eff }}(\mathrm{V} / \mathrm{m})$ measurements, with all the equipments in working conditions, resulted close to the sensitivity of the electric field probe $(1,0 \mathrm{~V} / \mathrm{m})$.

\section{(e) $M R$ room and other internal sources}

High frequencies $\mathrm{E}_{\text {eff }}(\mathrm{V} / \mathrm{m})$ measurements near the $\mathrm{MR}$ and into the gate room during the sequences activation, showed levels lower than $1,0 \mathrm{~V} / \mathrm{m}$.

Further investigations have been performed in other departments where the indoor DECT base stations for wireless communication are placed. These apparatus are generally located in the passageways, on the wall at a height of $2 \mathrm{~m}$ from the floor. High frequencies $\mathrm{E}_{\text {eff }}(\mathrm{V} / \mathrm{m})$ measurements have been carried out at a height of $1,0 \mathrm{~m}$ and $1,9 \mathrm{~m}$ from the floor close to the DECT systems. The $\mathrm{E}_{\text {eff }}(\mathrm{V} / \mathrm{m})$ levels within $1 \mathrm{~m}$ from the equipments, at a height of $1,9 \mathrm{~m}$ are comprised between 1,0 and $1,3 \mathrm{~V} / \mathrm{m}$.

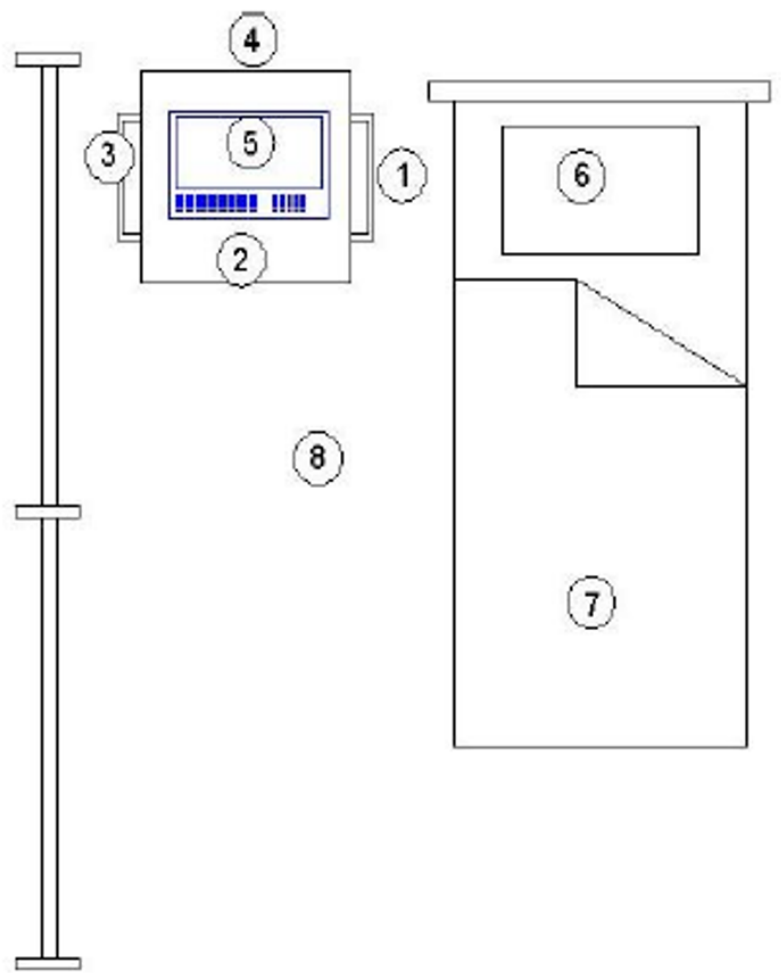

Figure 2

Specific equipments in a physiotherapy box.

\section{(f) External sources}

Further investigations have been carried out outside the NCI. In a radius of about $300 \mathrm{~m}$ a radiobase station for cellular communications is placed on the roof of a building. In the distance of a few $\mathrm{km}$ from the NCI, a tower with several broadcasting systems for radio, TV, and cellular radiobase stations is located. Investigations with the broad and the narrow band tools in the external area of the NCI show that these sources don't give a significant contribution to the electromagnetic field background in the area. Additional investigations inside the NCI, in particular in the physiotherapy division, allowed to detect a

Table 4: The $\mathbf{B}(\mu \mathbf{T})$ levels measured in the points reported in Fig. 3

\begin{tabular}{cc}
\hline Points of measurements & B $(\mu \mathbf{T})$ \\
\hline 1 & $\mathbf{8 0 , 0}$ \\
2 & 5,3 \\
3 & 2,0 \\
4 & 4,8 \\
5 & 11,1 \\
6 & 2,3 \\
7 & 1,1
\end{tabular}




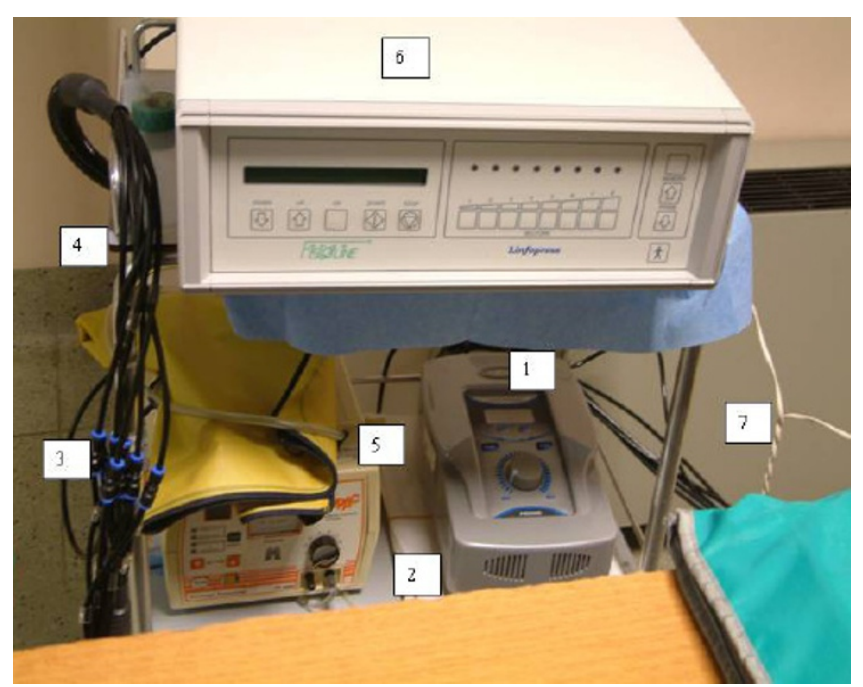

Figure 3

Results of the magnetic induction measurements near the press-therapy equipments.

weak electric field at the frequency of $1,9 \mathrm{GHz}$ produced by a radiobase station for the cellular networks (Fig. 6).

In Italy, people exposure to the ef-mf-emf is defined by two decrees $[8,9]$ in terms of three levels: (i) limits, levels that haven't to be exceeded in any circumstances for the protection from short terms effects; (ii) attention levels that have not to be exceeded into gambling areas, schools and buildings where people stay for more than 4 hours, as a precaution from the potential risks on health due to long time exposition; (iii) quality targets, levels to achieve in a long period in order to minimize people exposure. The respective levels for the protection of people exposure at high and low frequencies are reported in Tables 7 and 8.

The European recommendation [11] establishes basic restrictions and reference levels for limiting exposure. Basic restrictions are restrictions on exposure to time-varying electric, magnetic, and electromagnetic fields which are

Table 5: The $\mathrm{B}(\mu \mathrm{T})$ measurements in the open space reported in Fig. 4

\begin{tabular}{ccc}
\hline Points of measurements & \multicolumn{2}{c}{ B $(\mu \mathbf{T})$} \\
\cline { 2 - 3 } & $\mathrm{H} \mathrm{I} \mathrm{m}$ & $\mathrm{H} \mathrm{I.9} \mathrm{m}$ \\
\hline $\mathrm{I}$ & $\mathrm{I}, 7$ & $\mathrm{I}, 2$ \\
2 & 1,9 & $\mathrm{I}, \mathrm{I}$ \\
3 & 0,9 & 0,7 \\
4 & 0,3 & 0,2 \\
5 & 0,3 & $0, \mathrm{I}$ \\
6 & $0, \mathrm{I}$ & $0, \mathrm{I}$ \\
7 & 0,07 & 0,07 \\
\hline
\end{tabular}

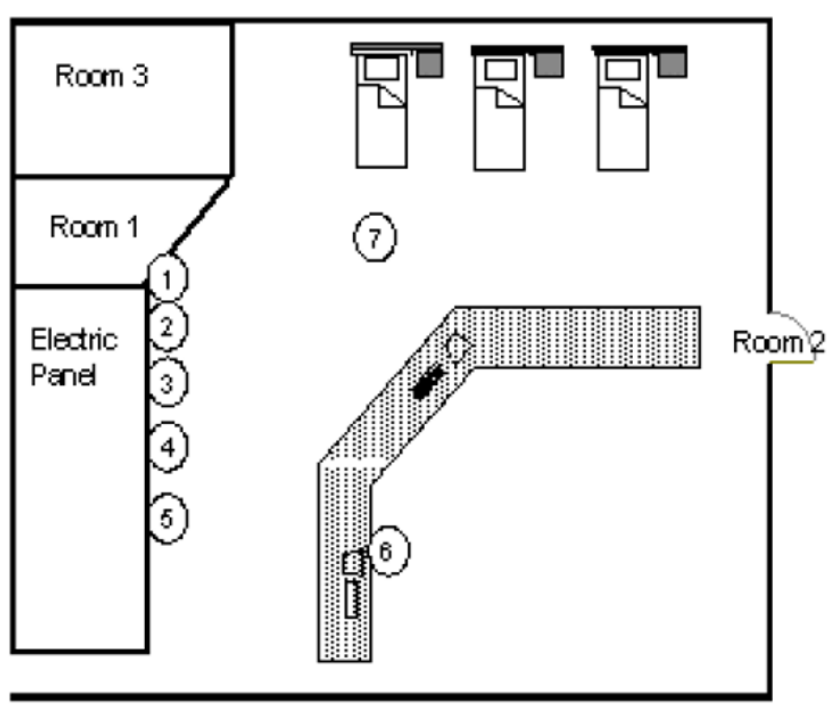

Figure 4

Results of the magnetic induction measurements $\mathbf{B}(\mu \mathrm{T})$ in the intensive care division.

based directly on established health effects and biological considerations. Depending upon the frequency of the field, the physical quantities used to specify these restrictions are magnetic flux density (B), current density (J), specific energy absorption rate (SAR), and power density (S). The reference levels are electric field strength (E), magnetic field strength (H), B, and S. Reference levels and basic restrictions have been developed following a thorough review of all published scientific literature. The criteria applied in the course of the review were designed to evaluate the credibility of the various reported findings; only established effects were used as a basis for the proposed exposure restrictions. Induction of cancer from long-term electromagnetic fields exposure was not considered. However, since there are safety factors of about 50 between the threshold values for acute effects and the basis restrictions, this recommendation implicitly covers also possible longterm effects in the whole frequency range. The respective levels are reported in Table 9.

The directive 2004/40/EC on the minimum health and safety requirements regarding the exposure of workers to the risks arising from electromagnetic fields, has been issued in the European Official Journal on May 25, 2004, together with its recent application in the Italian regulation [13]. It introduces measures protecting workers from the risks associated with emf, owing to their effects on the health and safety. The long-term effects, including possible carcinogenic effects due to exposure to time-varying ef$m f-e m f$ for which there is no conclusive scientific evidence establishing a causal relationship, are not addressed. Expo- 


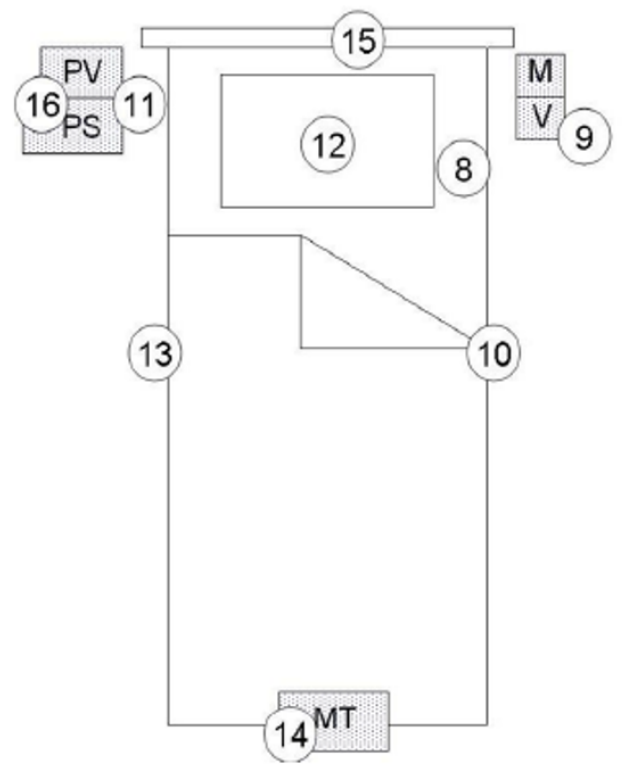

\section{Legenda}

M Monitor for the control of vital functions

V Ventilator

MT Engine of the anti-bedsore mattress

PV Volumetric pump

PS Syringe pump

\section{Figure 5}

Measurements near a patient's bed in the intensive care division. sure limit values and action values have been defined. The former are based directly on established health effects and biological considerations and compliance with these limits ensures that workers exposed to emf are protected against all known adverse health effects. The action values refer to the magnitude of directly measurable parameters, provided in terms of $\mathrm{E}, \mathrm{H}, \mathrm{B}$ and $\mathrm{S}$; the observance with these values ensure compliance with the relevant exposure limit. Action values are obtained from the exposure limit values according to the rationale used by the International Commission on Non-ionising Radiation Protection (ICNIRP) in its guidelines on limiting exposure to non-ionising radiation [13].

For the health staff in the NCI, the exposure levels are in agreement with the recommendations fixed by the international standards. However, for the health staff, the more restrictive Italian people long term exposure levels have been established as investigation levels. The results of the monitoring in the working areas frequented by patients and accompanies, near the equipments reported in Table 1 show a variability of the $\mathrm{B}(\mu \mathrm{T})$ measurements between 0,01 and $80 \mu \mathrm{T}$. The global statistical distribution of the $\mathrm{B}(\mu \mathrm{T})$ levels shows that most of the measurements are in the range $0,05<B=0,5 \mu \mathrm{T}$, with $25 \%$ of the levels registered in the surgical room, $9 \%$ in the press-therapy room and $15 \%$ in the physiotherapy division. The $89 \%$ of the $\mathrm{B}(\mu \mathrm{T})$ levels measured near electric and electronic devices used in diagnostics and in medical cures, in positions normally occupied by the patients during the treatments are within $3 \mu \mathrm{T}$, while $8 \%$ are within $10 \mu \mathrm{T}$. Only $3 \%$ of the measurements is higher than this level but

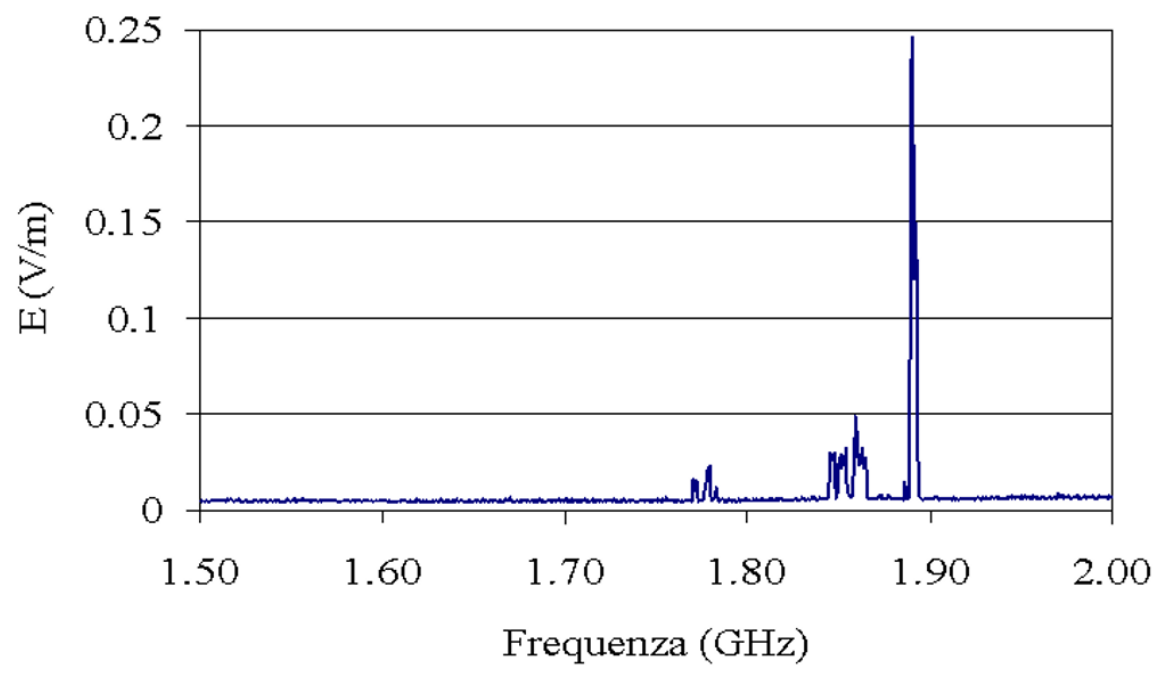

Figure 6

Results of the spectrum analysis carried out in the physiotherapy division. 
Table 6: The $\mathbf{B}(\mu \mathbf{T})$ measurements around the bed reported in Fig. 5

\begin{tabular}{cc}
\hline Points of measurements & B $(\mu \mathbf{T})$ \\
\hline 8 & 0,6 \\
9 & 0,4 \\
10 & 0,1 \\
11 & $\mathbf{7 , 0}$ \\
12 & 1,0 \\
13 & 0,1 \\
14 & 6,0 \\
15 & 0,7 \\
16 & $\mathbf{1 4 , 0}$ \\
\hline
\end{tabular}

within the restrictive limits imposed by the Italian law to regulate the exposure of the public to the $m f$. The last levels have been measured typically near the engine of the tools and near the electric power of the instrumentations in areas where the presence of the population is not scheduled. In order to minimize or reduce exposures, it is then sufficient to set the area around the devices, with the indications to the staff not to stay close to the devices in their operative conditions.

The exposure conditions of the patients for the extremely low frequencies and the emf in the intensive care are in accordance with the measurements carried out by Petrucci [14]. The results show that the type of equipments, their number and also their orientation respect to the patient is important to minimize $m f$ levels; in general, a collection of equipments should be avoided and a safety distance have to be adopted to avoid unnecessary exposures.

About the possible electromagnetic interference (EMI) with electronic equipments by radio waves coming from outside the hospital, we find $\mathrm{E}_{\text {eff }}(\mathrm{V} / \mathrm{m})$ sensibly lower than the values registered by Hanada et others [15]. However, measurements of the electromagnetic environment should be performed by each hospital specially in urban areas [16] where some sources could potentially induce strong electric field intensity causing malfunctions.

Table 7: Limits, levels and quality targets for people exposure to $100 \mathrm{kHz}-300 \mathrm{GHz}$ [8]

\begin{tabular}{|c|c|c|c|}
\hline Exposure limits & Electric field Intensity E (V/m) & Magnetic field intensity $H(\mathbf{A} / \mathbf{m})$ & Power density $D\left(\mathrm{~W} / \mathrm{m}^{2}\right)$ \\
\hline $0, \mathrm{I}<\mathrm{f} \leq 3 \mathrm{MHz}$ & 60 & 0,2 & - \\
\hline $3<\mathrm{f} \leq 3000 \mathrm{MHz}$ & 20 & 0,05 & 1 \\
\hline $3<\mathrm{f} \leq 300 \mathrm{GHz}$ & 40 & 0,01 & 4 \\
\hline \multicolumn{4}{|l|}{ Attention level } \\
\hline $0, \mathrm{I} \mathrm{MHz}<\mathrm{f} \leq 300 \mathrm{GHz}$ & 6 & 0,016 & $0,10(3 \mathrm{MHz}-300 \mathrm{GHz})$ \\
\hline \multicolumn{4}{|l|}{ Quality targets } \\
\hline $0, \mathrm{I} \mathrm{MHz}<\mathrm{f} \leq 300 \mathrm{GHz}$ & 6 & 0,016 & $0,10(3 \mathrm{MHz}-300 \mathrm{GHz})$ \\
\hline
\end{tabular}

Table 8: Limits, levels and quality targets for people exposure to power lines at $50 \mathrm{~Hz}$ [9]

\begin{tabular}{lccc}
\hline & Exposure limits & Attention levels & Quality targets \\
\hline $\mathrm{E}_{\text {eff }}(\mathrm{kV} / \mathrm{m})$ & 5 & - & - \\
$\mathrm{B}_{\mathrm{eff}}(\mu \mathrm{T})$ & 100 & 10 & 3 \\
\hline
\end{tabular}

Table 9: Reference levels for the general public from [II].

\begin{tabular}{|c|c|c|c|c|}
\hline \multicolumn{5}{|c|}{ Council Recommendation of I 2 July 1999 Reference levels for electric, magnetic and electromagnetic fields (0 Hz to $300 \mathrm{GHz}$, unperturbed rms values) } \\
\hline Frequency range & E-field strength (V/m) & $\mathrm{H}$-field strenght (A/m) & B-field $(\mu \mathrm{T})$ & $\begin{array}{l}\text { Equivalent plane wave power den- } \\
\text { sity Seq }\left(\mathrm{W} / \mathrm{m}^{2}\right)\end{array}$ \\
\hline $0-\mathrm{I} \mathrm{Hz}$ & - & $3,2 \times 104$ & $4 \times 104$ & - \\
\hline $\mathrm{I}-8 \mathrm{~Hz}$ & 10000 & $3,2 \times 104 / \mathrm{f}^{2}$ & $4 \times 104 / f^{2}$ & - \\
\hline $8-25 \mathrm{~Hz}$ & 10000 & $4000 / f$ & $5000 / f$ & - \\
\hline $0,025-0,8 \mathrm{~Hz}$ & $250 / f$ & $4 / f$ & $5 / f$ & - \\
\hline $0,8-3 \mathrm{kHz}$ & $250 / f$ & 5 & 6,25 & - \\
\hline $3-150 \mathrm{kHz}$ & 87 & 5 & 6,25 & - \\
\hline $0,15-I \mathrm{MHz}$ & 87 & $0,73 / f$ & $0,92 / f$ & - \\
\hline $\mathrm{I}-10 \mathrm{MHz}$ & $87 / f^{1 / 2}$ & $0,73 / f$ & $0,92 / f$ & - \\
\hline $10-400 \mathrm{MHz}$ & 28 & 0,073 & 0,092 & 2 \\
\hline $400-2000 \mathrm{MHz}$ & $1,375 f^{1 / 2}$ & $0,0037 \mathrm{fl}^{1 / 2}$ & $0,0046 \mathrm{f}^{1 / 2}$ & $f / 200$ \\
\hline $2-300 \mathrm{GHz}$ & 61 & 0,16 & 0,20 & 10 \\
\hline
\end{tabular}




\section{Conclusion}

The monitoring campaign of ef-mf-emf levels is suggested in areas equipped with a large number of electric and electronic devices used during the treatments, which can represent potential sources of ef-mf-emf. This investigation is also important for the safety of the workers and also for the patients subjected to the treatments and particularly vulnerable, as the oncological patients and also for the accompanists exposures.

The results of the electric and magnetic field measurements, carried out in the NCI, near devices normally used in diagnostics and in medical cures, in the departments of intensive care, physiotherapy, MR, press-therapy and in the surgical rooms, show that the exposure levels are lower than that established for the protection of people and workers.

However the monitoring campaign in the hospital environments is recommended when $\mathrm{E}_{\text {eff }}(\mathrm{V} / \mathrm{m})$ values beyond the threshold for the electromagnetic compatibility are registered [17-19].

The proper evaluation of the ef-mf-emf in the hospital environments allow to map their levels around the equipments, to choose tools with low emission of ef-mf-emf, and to design accurately and correctly the working areas, detecting potential interactions, reducing and minimizing the exposures.

\section{Competing interests}

The authors declare that they have no competing interests.

\section{Authors' contributions}

All authors contributed equally to this work, read and approved the final manuscript.

\section{Acknowledgements}

The authors are indebted to the Head and staff of Surgical and Intensive care, Physiotherapy and Press-therapy, Radiology Departments of IRE for their continued general support.

\section{References}

I. WHO Electromagnetic fields [http://www.who.int/peh-emf/en/]

2. Feychting M, Ahlbom A, Kheifets L: EMF and health. Annu Rev Public Health 2005, 26:165-89.

3. Kheifets L, Afifi AA, Shimkhada R: Public Health Impact of Extremely Low-Frequency Electromagnetic Fields. Environmental Health Perspectives 2006, I I 4(10): 1532-1537.

4. Huss A, Egger M, Hug K, Huwiler-Müntener K, Röösli M: Source of Funding and Results of Studies of Health Effects of Mobile Phone Use Systematic Review of Experimental Studies. Environmental Health Perspectives 2007, I I 5(I): I-4.

5. Valberg PA, van Deventer TE, Repacholi MH, Workgroup Report: Base Stations and Wireless Networks-Radiofrequency (RF) Exposures and Health Consequences. Environmental Health Perspectives 2007, I I 5(3):4I 6-424.

6. Cardis E, Richardson L, Deltour I, Armstrong B, Feychting M, Johansen C, Kilkenny M, McKinney P, Modan B, Sadetzki S, Schüz J, Swerdlow A, Vrijheid M, Auvinen A, Berg G, Blettner M, Bowman J, Brown J, Chetrit A, Christensen HC, Cook A, Hepworth S, Giles G,
Hours M, lavarone I, Jarus-Hakak A, Klaeboe L, Krewski D, Lagorio S, Lönn S, Mann S, McBride M, Muir K, Nadon L, Parent ME, Pearce N, Salminen T, Schoemaker M, Schlehofer B, Siemiatycki J, Taki M, Takebayashi T, Tynes T, van Tongeren M, Vecchia P, Wiart J, Woodward A, Yamaguchi N: The INTERPHONE study: design, epidemiological methods, and description of the study population. Eur J Epidemiol 2007, 22(9):647-664.

7. Fazzo L, Grignoli M, lavarone I, Polichetti A, De Santis M, Fano V, Forastiere F, Palange S, Pasetto R, Vanacore N, Comba P: Preliminary study of cause-specific mortality of a population exposed to $50 \mathrm{~Hz}$ magnetic fields, in a district of Rome municipality. Epidemiol Prev 2005, 29(5-6):243-252.

8. Italian DPCM del 8.7.2003: Exposure limits, attention levels and quality targets for protection of people exposure to electric, magnetic and electromagnetic fields produced with frequency between $100 \mathrm{kHz}$ and $300 \mathrm{GHz}$. G.U. 28/08/n. 1992003.

9. Italian DPCM 8.7.2003: Exposure limits, attention levels and quality targets for protection of people exposure to electric and magnetic fields produced by power lines at the frequency of $50 \mathrm{~Hz}$. G.U. 29/8/n. 2002003.

10. Guidelines for Limiting Exposure to Time-Varying Electric, Magnetic, and Electromagnetic Fields (up to $300 \mathrm{GHz}$ ). ICNIRP Health Physics 1998, 74:494-522.

11. Council Recommendation of 12 July 1999: On the limitation of exposure of the general public to electromagnetic fields. $(0$ $\mathrm{Hz}$ to $300 \mathrm{GHz}$ ) 1999/5/9/CE/30 1999.

12. Directive 2004/40/EC of the European Parliament and of the Council of 29 April 2004 on the minimum health and safety requirements regarding the exposure of workers to the risks arising from physical agents (electromagnetic fields). Eighteenth individual Directive within the meaning of Article 16(I) of Directive 89/39//EEC.

13. Italian D. Lgs. 19 novembre n. 257: Attuazione della direttiva 2004/40/CE sulle prescrizioni minime di sicurezza e di salute relative all'esposizione dei lavoratori ai rischi derivanti dagli agenti fisici (campi elettromagnetici). G.U. I//0//2008, n. 9 2007.

14. Petrucci N: Exposure of the critically ill patient to extremely low-frequency electromagnetic fields in the intensive care environment. Intensive Care Med I999, 25:847-85I.

15. Hanada E, Kodama K, Takano K, Watanabe Y, Nose Y: Possible electromagnetic interference with electronic medical equipment by radio waves coming from outside the hospital. J Med Syst 200I, 25(4):257-267.

16. Giliberti C, Bedini A, Palomba R, D'Emilia E, Magli CV, Giuliani L: The electromagnetic field background in the urban area of Rome (Italy). The situation until 200 I Proceedings of the IEEE 6th International Symposium on electromagnetic compatibility and electromagnetic ecology: 2I-24 June 2005; Saint Petersburg :208-2I 2.

17. Shaw Cl, Kacmarek RM, Hampton RL, Riggi V, El Masry A, Cooper JB, Hurford WE: Cellular phone interference with the operation of mechanical ventilators. Crit Care Med 2004, 32(4):928-931.

18. Morrissey J]: Mobile phones in the hospital: improved mobile communication and mitigation of EMI concerns can lead to an overall benefit to healthcare. Health Phys 2004, 87(I):82-88.

19. Barbaro V, Bartolini P, Benassi M, Di Nallo AM, Reali L, Valsecchi M: Electromagnetic interference of GSM cellular phones and UHF radios with intensive-care and operating-room ventilators. Biomedical instrumentation and technology 2000, 34:36I-369. 